\title{
Влияние условий отжига подложки (001)InP в потоке As на качество эпитаксиальных слоёв InAlAs
}

Д.В. Дмитриев, А.И. Торопов, А.М. Гилинский, Д.А. Колосовский, Т.А. Гаврилова, А.С. Кожухов, К.С. Журавлёв

\author{
Институт физики полупроводников им. А.В. Ржанова СО РАН, \\ Новосибирск, 630090, пр. Ак. Лаврентьева, 13 \\ тел: (383)330-69-45, факс: (383)333-27-71, эл. почта: ddmitriev@isp.nsc.ru
}

DOI 10.34077/RCSP2019-102

В работе показана зависимость плотности структурных дефектов в решёточно-согласованных слояx InAlAs от условий отжига подложки (001)InP в потоке As. Отработана технология отжига, на основе которой синтезированы структуры мощных СВЧ фотодиодов и модуляторов.

Гетероструктуры на основе слоев InAlAs решёточно-согласованных с подложкой (001)InP, в настоящее время привлекают большое внимание исследователей из-за применения в широком спектре современных приборов[1]. Характеристики приборов напрямую зависят от качества гетероэпитаксиальных слоёв [2]. В работе показана зависимость плотности структурных дефектов в решёточно-согласованных слоях InAlAs от условий отжига подложки InP в потоке As.

Образцы выращены методом МЛЭ на установке Riber Compact-21T, оснащенной с системой дифракции быстрых электронов на отражении. Для роста использовались полуизолирующие легированные $\mathrm{Fe}(001) \mathrm{InP}$ подложки фирмы АXT.

Подложки отжигались в широком диапазоне температур $500-560^{\circ} \mathrm{C}$, для удаления окисного слоя до появления сверхструктуры (4x2). Отжиг проводился в потоке мышьяка, препятствующем разложению подложки и образованию индиевых капель. Поток мышьяка варьировался в широком диапазоне $(0.5-7)^{*} 10-5$ Торр. В процессе отжига происходит замещение атомов фосфора атомами мышьяка и на поверхности подложки образуется слой InAs. Методом сканирующей электронной микроскопией (CЭM) в режиме энергодисперсионной спектроскопии (EDS) было показано, что этот слой может достигать нескольких нанометров, в зависимости от условий отжига. Постоянная

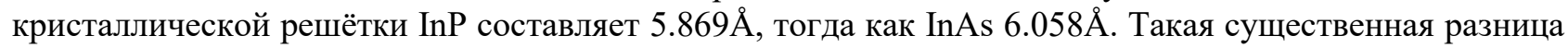
приводит к решёточному рассогласованию на начальных этапах роста слоёв InAlAs и возникновению напряжений, которые релаксируют в виде прорастающих дислокаций. На АCM картинах поверхности наблюдаются структурные дефекты в виде ямок сформированные комплексами дислокаций. Плотность ямок на поверхности слоя InAlAs увеличивается с увеличением толщины слоя InAs на гетерогранице слой/подложка, и может достигать $10^{-9} \mathrm{~cm}^{2}$. Толщина слоя InAs зависит от температуры отжига и времени экспозиции подложки в потоке мышьяка. В работе экспериментально полученные оптимальные условия отжига: температура подложки $<520^{\circ} \mathrm{C}$, эквивалентный поток мышьяка $<1,6 \times 10^{-5}$ Торр, время экспозиции при формировании сверхструктуры $(4 \mathrm{x} 2)<30$ секунд. При этих условиях с поверхности удаляются окислы, но не формируется существенный слой InAs, что позволяет синтезировать высококачественные слои InAlAs для оптоэлектронных приборов. Нами были получен мощные СВЧ фотодиоды 1.55 мкм спектрального диапазона, с частотами до 40Ггц, а также продемонстрированы гетероэпитаксиальные структуры для модуляторов.

АСМ и СЭМ исследования проводились на оборудовании ЦКП «Наноструктуры».

\section{Лumepamypa}

[1] X. Meng, C.H. Tan, S. Dimler, J.PR David, J.S. Ng, Optics Express vol. 22, iss. 19, p.22608. (2014).

[2] I.B. Chistokhin, M.S. Aksenov, N.A. Valisheva, D.V. Dmitriev, A.P. Kovchavtsev, A.K. Gutakovskii, I.P. Prosvirin, K.S. Zhuravlev, Materials Science in Semiconductor Processing 74, 193 (2018). 